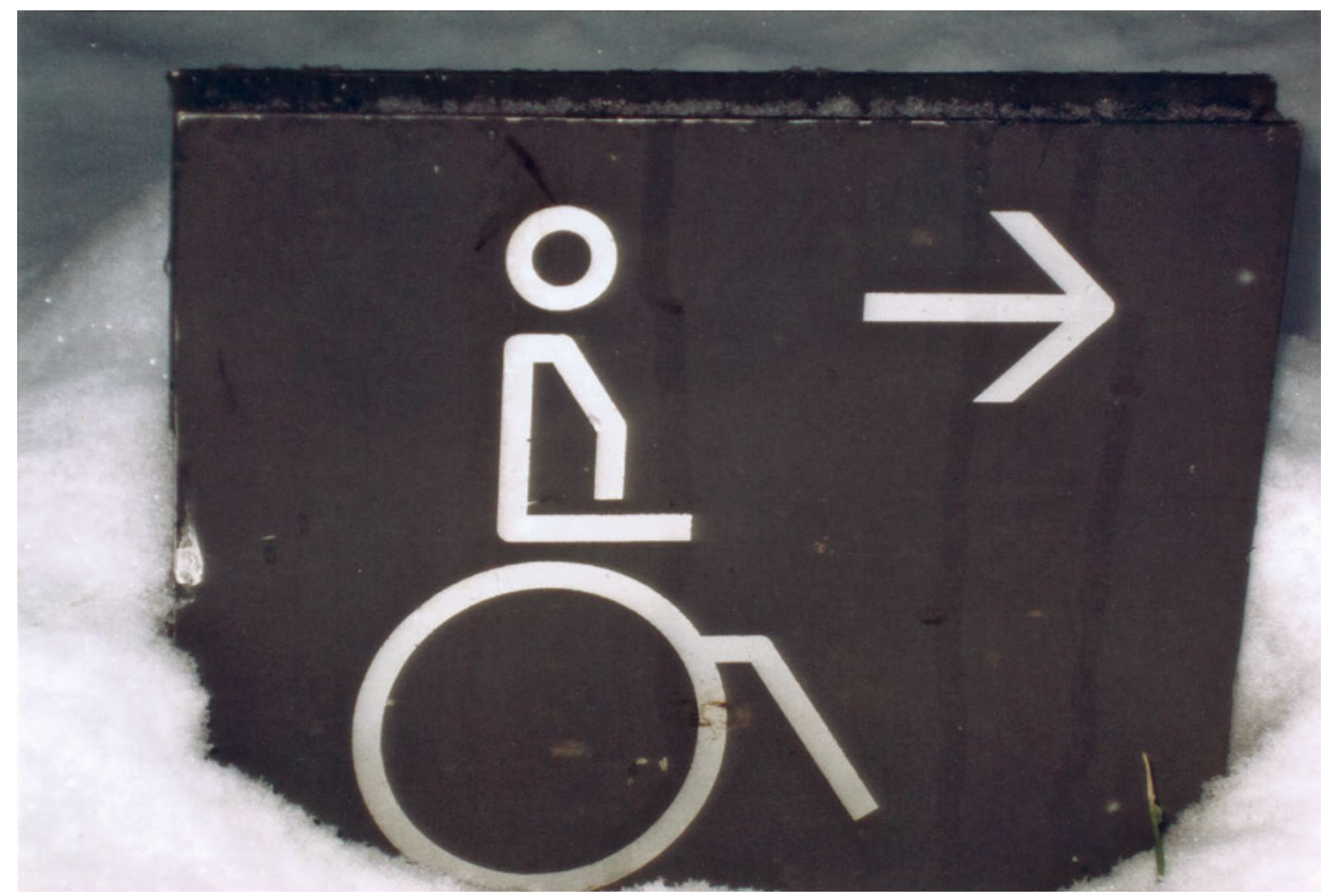

\title{
Das schwarze Schild
}

\section{Enrico Danieli}

Dr. med., Facharzt für Allgemeine Innere Medizin, Mitglied FMH

Korrespondenz:

Dr. med. Enrico Danieli

Via ai Colli 22

CH-6648 Minusio

e.b.danieli[at]bluewin.ch
Es sind verschiedene Dinge, die zusammenkommen und zurückschrecken lassen. Gut gemeint ist selten absichtslos, aber oft unausgewogen, unbedacht. Missfallen erweckt die schwarze Platte, das schwarze Schild mit weissem Pfeil und Rollstuhl. Welchem Zweck dient schwarz als Signaltafel für das, das einem heimgesucht und gefällt hat? Schwarz ist Verdruss, ist Untergang, ist Trauer, Tod. Wird schwarz denen zugeteilt, deren Schicksal sich schon erfüllt hat, Menschen, letztlich, ohne Existenzberechtigung? Die Darstellung der Rollstuhlabhängigkeit ist, natürlich, ein Symbol, eine Skizze, eineAbstraktion, zeitgemäss im DesignerStil. Einprägsam und eindeutig die Aussage - doch stört das Fehlen der Beine. Als ob ein Oberkörper ohne Beine das Übliche wäre.

Das labile Gleichgewicht nimmt die grosse Gefahr des Kippens in Kauf; doch Abstraktionen kennen keine
Rücksicht. Dass am Rad eine Halterung für die Beine vorgesehen ist, macht die Sache unerträglich: diese Stütze erweckt den Eindruck, dass Beine unabhängig vom Körper existieren. Und die Pfeilrichtung nach rechts. Zur Abgabe von Beinen? Und Schnee, viel Schnee, der Weg zur Abgabestelle selbstverständlich unpassierbar für Menschen mit Rollstühlen. Wer wird sich die Zeit nehmen wollen, einen Rollstuhlweg freizuschaufeln? Oder sind die Schwarzfahrer gemeint, die, auf Grund von Andersartigkeit, unrechtmässig zu leben beanspruchen? Schwarz heisst unbunt, heisst leer, schwarz wirft nichts zurück: keinen Glanz, kein Licht, kein Leben. Und genau so soll sie sein, die schwarze Tafel, sie nimmt vorweg, was früh kommt: den Tod.

\section{Bildnachweis}

Foto: Enrico Danieli 